\title{
Comparison of Wrist Tapping Parameters in Healthy Adults with and Without Anxiety Using a Modified Original Technique
}

\author{
Ekaterina A. Narodova, $\mathrm{PhD}^{1 *}$; Vyacheslav A. Rudnev, $\mathrm{PhD}, \mathrm{ScD}^{1}$; Natalia A. Shnayder ${ }^{1,2}$; \\ Andrey A. Narodov, PhD, ScD ${ }^{1}$; Evgeniy E. Erakhtin ${ }^{1}$ \\ ${ }^{I}$ V.F. Voino-Yasenetsky Krasnoyarsk State Medical University, Krasnoyarsk, Russia \\ ${ }_{2}^{2}$ St. Petersburg V.M. Bekhterev Psychoneurological Research Institute, St. Petersburg, Russia
}

\begin{abstract}
The aim of the present study was to assess the main characteristics of the tempo-rhythm in healthy adults.

Materials and Methods: We examined 60 healthy adults without neurological and endocrinological pathology. Participants were divided into 2 groups. In Group 1 there were 33 adults without deviations on the scale of anxiety and depression were, and in Group 2, there were 27 persons with subclinically expressed anxiety according to the test results. The test was conducted using hospital anxiety and depression scale HADS. The study was conducted using a modified original technique "Method of exogenous rhythmic stimulation influence on an individual human rhythm."

Results: We found that anxiety statistically significant affects the quantitative and qualitative parameters of wrist tapping (individual rhythm and rhythm stability) in healthy adults.

Conclusion: The obtained data can be used in neurorehabilitation for adult patients with a wide range of neurological disorders, including epilepsy. (International Journal of Biomedicine. 2018;8(3):240-243.)
\end{abstract}

Key Words: rehabilitation $\bullet$ wrist tapping $\bullet$ neurology $\bullet$ epilepsy $\bullet$ anxiety

\section{Introduction}

Tapping is a psychomotor test that can be used to assess the psychophysiological brain functions, in particular, the time perception. ${ }^{(1,2)}$ Tapping without any external influence, with the preferred test speed, is a "biological constant", which reflects the speed of nervous processes and endogenous rhythmic processes in the central nervous system. ${ }^{(3)}$ Interest in the study of wrist tapping remains high due to its fundamental character. Specifically, according to V. A. Rudnev (1982), the cyclical nature of movements in wrist tapping is a natural statistical regularity that can be considered as a measurement standard to which different parameters can be compared. The study of these biologically appropriate movements makes it possible to establish a pattern of certain rates and rhythms that occurs in the pathology at different levels of the human nervous system. ${ }^{(4)}$

Methods of tempo-rhythm correction take a special place in modern neurology and neurorehabilitation. ${ }^{(5)}$ The

*Corresponding author: Ekaterina A. Narodova, PhD. Krasnoyarsk State Medical University named after Prof. V.F. VoinoYasenetsky, Krasnoyarsk, Russia. E-mail: katya n2001@mail.ru synergy of the wrist tapping was chosen as the object of our study. We studied three quantitative parameters: (1) movement from the tapping point - component " $b$," (2) movement to the tapping point - component "a," and (3) the time of the full cycle - "b+a").

The aim of the present study was to assess the main characteristics of the tempo-rhythm in healthy adults.

\section{Materials and Methods}

The present study was approved by the local Ethics Committee of Professor V.F. Voino-Yasenetsky Krasnoyarsk State Medical University (Record No. 77/2017 dated 26.06.2017). The study was performed at the Center for Neurology, Epileptology, Neurogenetics and Brain Research of the University Clinic; the Department of Nervous Diseases with a course of medical rehabilitation; the Department of Medical Genetics and Clinical Neurophysiology of the Institute of Postgraduate Education; and also at the Department of Personalized Psychiatry and Neurology of the V.M. Bekhterev National Research Medical Center for Psychiatry and Neurology (St. Petersburg), within the agreement on scientific cooperation with the center. 
A total of 60 healthy volunteers ( 28 men, 32 women) participated in the study. Participants were divided into 2 groups. In Group 1 there were 33 adults without deviations on the scale of anxiety and depression were, and in Group 2, there were 27 persons with subclinically expressed anxiety according to the test results. The test was conducted using hospital anxiety and depression scale HADS. ${ }^{(6)}$ The study was conducted using a modified original technique "Method of exogenous rhythmic stimulation influence on an individual human rhythm” [RF patent №2606489 dated 10.01.2017]. Modification of the method included carrying out the study of the patients' individual rhythms without the use of exogenous rhythmic stimulation (Fig.1). The study was conducted in the morning with the exclusion of external sensory stimuli (loud sound, bright light) and other people, except the doctor and the volunteer, during the tapping procedure. Room temperature was maintained at $22-25^{\circ} \mathrm{C}$.

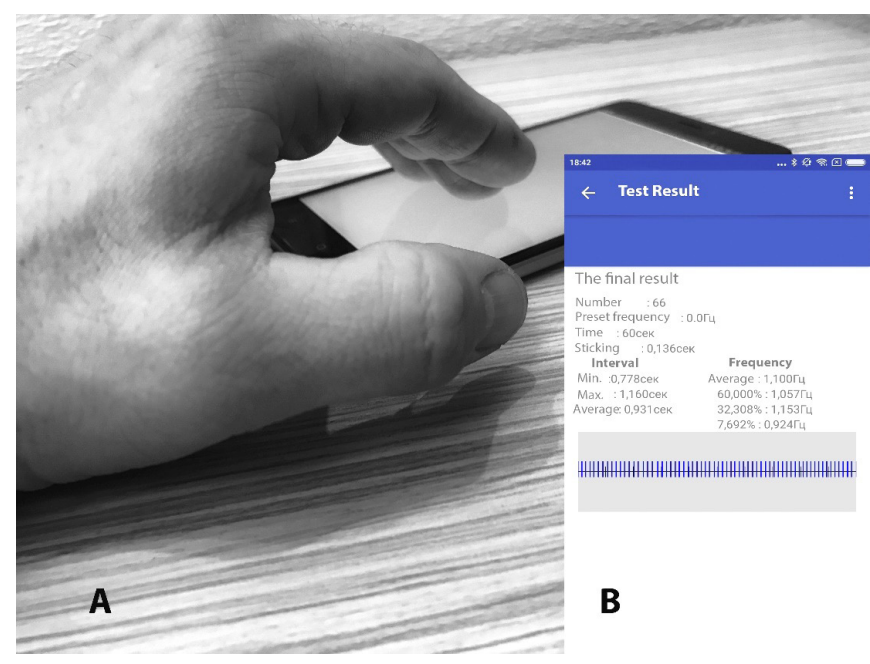

Fig. 1. Method of exogenous rhythmic stimulation influence on an individual human rhythm [RF patent №2606489]

A - General view of the study

$\mathrm{B}$ - An example of the results of wrist tapping in healthy volunteers

\section{Inclusion criteria:}

-Healthy adults

-Signed voluntary informed consent

-Male and female

-The age period: the youth (males 17-21; females 16-20

years); the first period of middle age (males 22-35 years; females 21-35 years); the second period of middle age (males 36-60 years; females 36-55 years)

-Russian-speaking Europeans

\section{Exclusion criteria:}

-Children and adolescents

-Refusal to participate in this study

-Participation in other studies

-Acute and chronic neurological, psychiatric

and endocrinological disorders at the time of examination

-Alcohol intake ( 2 or more drinks during the last 2 weeks)

-Use of narcotic drugs at the time of the study and in history
Volunteers did not receive any payment for participating in this study. The researchers did not receive any payment for conducting the study.

\section{Research procedure}

The technique included finger tapping on the surface of the device (Xiaomi smartphone based on Android, China), followed by the registration of the time parameters of this process in the author's program based on the modified technique "Method of exogenous rhythmic stimulation influence on an individual human rhythm" [RF patent №2606489 dated 10.01.2017].

During the task implementation, the mechanogram where vertical strokes display the contact of the finger with the screen appears on the screen of the device. (Fig.1). We analyzed the following parameters: total number of taps per minute, average frequency of taps per second $(\mathrm{Hz})$, the rhythm stability - the proportion of the frequency of taps (in percentage), the individual rhythm - the frequency with the highest percentage of occurrence in the sample; the delay time of the subsequent tap (in seconds), the intervals between taps, including the maximum interval (seconds), the minimum interval (seconds), and the average interval (seconds). Also, the registration of an individual "minute" was carried out with the use of a stopwatch. Volunteers were asked to count 60 seconds to themselves, after which they had to say "stop". Time on the stopwatch stopped, the result was recorded.

\section{Participants}

Group I consisted of 33 adults ( 13 men and 20 women) without deviations on the scale of anxiety and depression (0-7 points). In Group 1, the mean age was $33.69 \pm 12.06$ years, the median age was $32[22 ; 46.5]$ years. Group 2 consisted of 27 adults (15 men and 12 women) with subclinically expressed anxiety (8-10 points). In Group 2, the mean age was $32.4 \pm 11.46$ years, the median age was 29 [22; 42] years.

\section{Statistical analysis}

Statistical analysis was performed using IBM SPSS Statistics 23. Continuous variables were presented as mean \pm $\mathrm{SD}$ and as median (interquartile range [IQR]). Means of 2 continuous normally distributed variables were compared by independent samples Student's t test. Mann-Whitney U test and Kruskal-Wallis test were used, respectively, to compare means of 2 and 3 or more groups of variables not normally distributed. A value of $P<0.05$ was considered significant.

\section{Results and Discussion}

The main characteristics of wrist tapping in Group 1 using a modified technique "Method of exogenous rhythmic stimulation influence on an individual human rhythm" are presented in Table 1. The main characteristics of wrist tapping in Group 2 are presented in Table 2.

In men of Group 1, the median of an individual "minute" was higher than in women of the same group $(64$ [58.5; 69] seconds against $55[49.25 ; 60.75]$ seconds, respectively), and the average value was $63.3 \pm 13.21$ versus $56.05 \pm 9.6$ seconds, respectively. However, gender differences were not statistically significant. 
Table 1.

Tapping parameters in Group 1

\begin{tabular}{|c|c|c|c|c|c|c|c|}
\hline \multirow{2}{*}{ Variable } & \multicolumn{3}{|c|}{$\mathrm{Me}\left[\mathrm{P}_{25} ; \mathrm{P}_{75}\right]$} & \multicolumn{3}{|c|}{$\mathrm{M} \pm \mathrm{SD}$} & \multirow{2}{*}{$P$-value } \\
\hline & All N & Male n1 & Female n2 & All N & Male n1 & Female n 2 & \\
\hline $\begin{array}{l}\text { Volunteers age, } \\
\text { yrs }\end{array}$ & $32[22 ; 46.5]$ & $39[25.5 ; 49]$ & $22[21 ; 42.75]$ & $33.69 \pm 12.06$ & $37.53 \pm 12.05$ & $31.2 \pm 11.68$ & 0.6 \\
\hline $\begin{array}{l}\text { Individual minute, } \\
\text { sec }\end{array}$ & $59[50.5 ; 66]$ & $64[58.5 ; 69]$ & 55 [49.25;60.75] & $58.9 \pm 11,54$ & $63.3 \pm 13,21$ & $56.05 \pm 9,6$ & 0.08 \\
\hline $\begin{array}{l}\text { Rhythm stability, } \\
\%\end{array}$ & 49 [40.7;52.69] & $50.72[40.7 ; 51.71]$ & $46.82[40.1 ; 56.03]$ & $49.12 \pm 11.55$ & $46.95 \pm 7.46$ & $50.54 \pm 13.57$ & 0.7 \\
\hline $\begin{array}{l}\text { Delayed time of } \\
\text { the tap, sec }\end{array}$ & $0.1[0.08 ; 0.18]$ & $0.09[0.07 ; 0.19]$ & $0.11[0.09 ; 0.2]$ & $0.13 \pm 0.09$ & $0.11 \pm 0.04$ & $0.15 \pm 0.11$ & 0.5 \\
\hline $\begin{array}{l}\text { Maximum interval } \\
\text { between taps, sec }\end{array}$ & $1.33[1.09 ; 1.62]$ & $0.08[0.07 ; 0.16]$ & $1.38[1.17 ; 1.8]$ & $4.31 \pm 1.33$ & $1.33 \pm 0.35$ & $6.25 \pm 21.13$ & 0.4 \\
\hline $\begin{array}{l}\text { Minimum interval } \\
\text { between taps, sec }\end{array}$ & $0.63[0.51 ; 0.7]$ & $0.66[0.63 ; 0.7]$ & $0.6[0.48 ; 0.73]$ & $0.58 \pm 0.2$ & $0.65 \pm 0.08$ & $0.54 \pm 0.24$ & 0.7 \\
\hline Total number of taps & $68[60 ; 73]$ & $71[55 ; 74.5]$ & $66[61.5 ; 72.75]$ & $66.8 \pm 8.08$ & $66.84 \pm 9.34$ & $64.66 \pm 12.44$ & 0.9 \\
\hline
\end{tabular}

Table 2.

Tapping parameters in Group 2

\begin{tabular}{|c|c|c|c|c|c|c|c|}
\hline \multirow{2}{*}{ Variable } & \multicolumn{3}{|c|}{$\mathrm{Me}\left[\mathrm{P}_{25} ; \mathrm{P}_{75}\right]$} & \multicolumn{3}{|c|}{$\mathrm{M} \pm \mathrm{SD}$} & \multirow{2}{*}{$P$-value } \\
\hline & All N & Male n1 & Female n2 & All N & Male n1 & Female n2 & \\
\hline $\begin{array}{l}\text { Volunteers age, } \\
\text { yrs }\end{array}$ & $29[22 ; 42]$ & $29[24 ; 44]$ & $28[21.25 ; 40.75]$ & $32.4 \pm 11.46$ & $33.53 \pm 12.33$ & $31 \pm 10.62$ & 0.24 \\
\hline $\begin{array}{l}\text { Individual minute, } \\
\mathrm{sec}\end{array}$ & $53[44 ; 59]$ & $53[43 ; 58]$ & $52[46.5 ; 62.5]$ & $52.74 \pm 10.32$ & $51.2 \pm 9.23$ & $54.67 \pm 1.66$ & 0.5 \\
\hline $\begin{array}{l}\text { Rhythm stability, } \\
\%\end{array}$ & $52.94[48.8 ; 54.65]$ & $50.57[47.75 ; 54.65]$ & $54.02[50.92 ; 56.51]$ & $52.32 \pm 7.88$ & $51.3 \pm 9.27$ & $53.58 \pm 5.86$ & 0.13 \\
\hline $\begin{array}{l}\text { Delayed time of } \\
\text { the tap, sec }\end{array}$ & $0.1[0.07 ; 0.18]$ & $0.1[0.08 ; 0.19]$ & $0.08[0.07 ; 0.18]$ & $0.12 \pm 0.062$ & $0.12 \pm 0.06$ & $0.11 \pm 0.06$ & 0.7 \\
\hline $\begin{array}{l}\text { Average interval } \\
\text { between taps, sec }\end{array}$ & $0.64[0.49 ; 0.69]$ & $0.66[0.55 ; 0.69]$ & $0.55[0.38 ; 0.71]$ & $0.58 \pm 0.14$ & $0.61 \pm 0.1$ & $0.55 \pm 0.17$ & 0.4 \\
\hline $\begin{array}{l}\text { Minimum interval } \\
\text { between taps, sec }\end{array}$ & $0.41[0.24 ; 0.55]$ & $0.44[0.19 ; 0.55]$ & $0.39[0.27 ; 0.55]$ & $0.38 \pm 0.17$ & $0.36 \pm 0.2$ & $0.41 \pm 0.15$ & 0.9 \\
\hline Total number of taps & $93[87 ; 121]$ & $91[55 ; 74.5]$ & $109[83.5 ; 158.5]$ & $109 \pm 34.79$ & $102 \pm 25.76$ & $119.4 \pm 42.83$ & 0.38 \\
\hline
\end{tabular}

In Group 2, the median of an individual "minute" in men was 53 [43; 58] seconds versus 52 [46.5; 62.5] seconds in women; the average value was $51.2 \pm 9.23$ seconds versus $54.67 \pm 11.66$ seconds. As with Group 1, gender differences did not reach statistical significance in Group 2. Considering this fact, we neglected gender differences in both groups and compared the average values of individual minutes; we did not find a statistically significant difference between these parameters (Table 3). The median of individual rhythm in men and women of Group I was $1.13 \mathrm{~Hz}$ versus $1.53 \mathrm{~Hz}$ in Group 2. 
Table 3.

Comparison of wrist tapping parameters in Groups 1 and 2

\begin{tabular}{|c|c|c|c|c|c|}
\hline \multirow{2}{*}{ Variable } & \multicolumn{2}{|c|}{$\mathrm{Me}\left[\mathrm{P}_{25} ; \mathrm{P}_{75}\right]$} & \multicolumn{2}{|c|}{$\mathrm{M} \pm \mathrm{SD}$} & \multirow{2}{*}{$P$-value } \\
\hline & Group 1 & Group 2 & Group 1 & Group 2 & \\
\hline Volunteers age, yrs & $32[22 ; 46.5]$ & $29[22 ; 42]$ & $33.69 \pm 12.06$ & $32.4 \pm 11.46$ & 0.2 \\
\hline Individual minute, sec & $59[50.5 ; 66]$ & $53[44 ; 59]$ & $58.9 \pm 11.54$ & $52.74 \pm 10.32$ & 0.06 \\
\hline Individual rhythm, $\mathrm{Hz}$ & $1.13[0.99 ; 1.21]$ & $1.53[1.45 ; 1.98]$ & $1.11 \pm 0.13$ & $1.82 \pm 0.58$ & 0.0000 \\
\hline Rhythm stability, \% & $49[40.7 ; 52.69]$ & $52.94[48.8 ; 54.65]$ & $49.12 \pm 11.55$ & $52.32 \pm 7.88$ & 0.019 \\
\hline Delayed time of the tap, sec & $0.1[0.08 ; 0.18]$ & $0.1[0.07 ; 0.18]$ & $0.13 \pm 0.09$ & $0.12 \pm 0.06$ & 0.07 \\
\hline Maximum interval between taps, sec & $1.33[1.09 ; 1.62]$ & $0.8[0.66 ; 1.11]$ & $4.31 \pm 1.33$ & $0.92 \pm 0.38$ & 0.0001 \\
\hline Average interval between taps, sec & $0.87[0.82 ; 1]$ & $0.64[0.49 ; 0.69]$ & $0.91 \pm 0.11$ & $0.58 \pm 0.14$ & 0.0000 \\
\hline Minimum interval between taps, sec & $0.63[0.51 ; 0.7]$ & $0.41[0.24 ; 0.55]$ & $0.58 \pm 0.2$ & $0.38 \pm 0.17$ & 0.0000 \\
\hline Total number of taps & $68[60 ; 73]$ & $93[87 ; 121]$ & $66.8 \pm 8.08$ & $109 \pm 34.79$ & 0.0000 \\
\hline
\end{tabular}

We found a statistically significant difference between these parameters. A statistically significant difference was also found between the parameters of rhythm stability and the intervals between taps in Group 1 and Group 2. Thus, the most stable rhythm and the smallest interval between taps were detected in Group 2. We found no statistically significant differences in the delayed time of the tap between the study participants from Group 1 and Group 2. Thus, with the subsequent use of the reference corridors of the wrist tapping characteristics, we can ignore gender differences in the group of adult volunteers. ${ }^{(7)}$ Also, it is necessary to take into account the effect of the presence of anxiety at the time of the study, since anxiety affects the quantitative and qualitative parameters of wrist tapping (individual rhythm and rhythm stability).

\section{Conclusion}

Studying how the anxiety level influences the parameters of wrist tapping in healthy adult volunteers, using a modified original technique "Method of exogenous rhythmic stimulation influence on an individual human rhythm," allowed us to determine the reference corridors for further application of this method in diagnostic testing and rehabilitation of patients suffering from various neurological disorders, including epilepsy.

\section{Competing Interests}

The authors declare that they have no competing interests.

\section{References}

1. Bykov YN. [Cerebral integrated mechanisms (Message 2)]. Siberian Medical Journal (Irkutsk). 2001;(2):4-9. [Article in Russian].

2. Narodova EA, Shnayder NA, Narodova VV, Dmitrenko DV, Artyukhov IP. The Role of Non-Drug Treatment Methods in the Management of Epilepsy. International Journal of Biomedicine. 2018;8(1):9-14. doi: 10.21103/Article8(1)_BR. 3. Pogelt B, Roth N, Poget A. Automated rhythmic movements and their control under different experimental conditions. Biomed Biochim Acta. 1984;43(4):485-491.

4. Rudnev VA. [Functional diagnostics and restoration of voluntary movements in the pathology of the central nervous system]. Krasnoyarsk: Publishing house of Krasnoyarsk University; 1982. [In Russian].

5. Narodova EA, Rudnev VA, Shnayder NA, Narodova VV, Erahtin EE, Dmitrenko DV, Shilkina OS, Moskaleva PV, Gazenkampf KA. Parameters of the Wrist Tapping using a Modification of the Original Method (Method of exogenous rhythmic stimulation influence on an individual human rhythm). International Journal of Biomedicine. 2018;8(2):155158. doi: 10.21103/Article8(2)_OA10.

6. Zigmond AS, Snaith RP. The hospital anxiety and depression scale. Acta Psychiatr Scand. 1983;67(6):361-370.

7. Narodova EA, Narodova VV, Narodov AA, Erakhtin EE. Method of exposure to individual human rhythm by means of exogenous rhythm stimulation. RU № 2606489. register. 26.03.15; published 10.01.17; Bul. № 1. [In Russian]. 